\title{
Help collect data on patient waiting times in gastroenterology: \\ PAGE IV - Improving Access to \\ Gastroenterology Services in Canada practice audit program
}

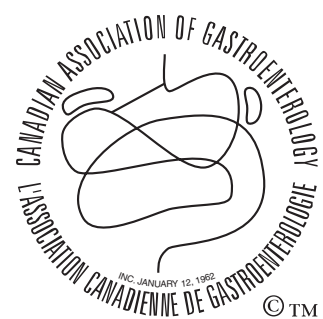

En français voir page 265

\begin{abstract}
What is PAGE IV?
The Practice Audit in GastroEnterology (PAGE) IV program will collect much-needed data on how long patients across Canada wait for gastroenterology consultation and procedures. Physicians record basic referral data on a personal digital assistant (PDA) for five days; one patient audit requires about three minutes to enter.
\end{abstract}

Why is PAGE IV important?

PAGE will provide key data for provincial/regional gastroenterology associations to assist them in measuring access to care and exploring possible solutions with provincial health ministries where problems exist. The data will also help in the development of a human resource plan for gastroenterology (for more information visit: http://www.cag-acg.org/whatsnew/hrplanningproject.htm).

Who can participate?

Gastroenterologists and gastroenterology internists are encouraged to participate provided that: their practice routinely records the date that patients are first referred; and the majority of patients seen are NOT follow-ups/repeat procedures.

How does it work?

Physicians can sign up online at the Canadian Association of Gastroenterology (CAG) Web site $<$ www.cag-acg.org>, or by calling 1-888-780-0007, faxing
905-829-0242 or e-mailing the CAG National Office (sandra@cag-acg.org). CAG will mail an information package and once the necessary forms are returned, an AstraZeneca representative will drop off the PDA and walk the physician through how the program works. The representative will return to download the data to the secure, password-protected database and erase them from the PDA.

Are my data confidential?

PDA data cannot be read without a 'key' held by Isis Digital Media, the company responsible for the technology behind PAGE IV. Once data are final, participants will be able to review their personal data and aggregate national, provincial or regional data - however individual results remain confidential.

For more information on PAGE IV... click this icon on the CAG Web site home page:

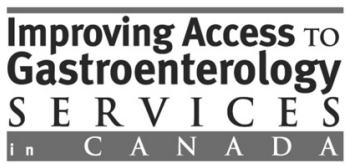

or visit: http://www.cag-acg.org/sponsors/page.htm

The CAG is proud to acknowledge its Benefactor Corporate Sponsors:

Abbott Laboratories Ltd.

Janssen-Ortho Inc.
AstraZeneca Canada Inc.

Pfizer Canada Inc.
Axcan Pharma Inc.

Schering Canada Inc. 


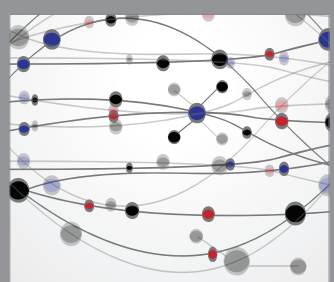

The Scientific World Journal
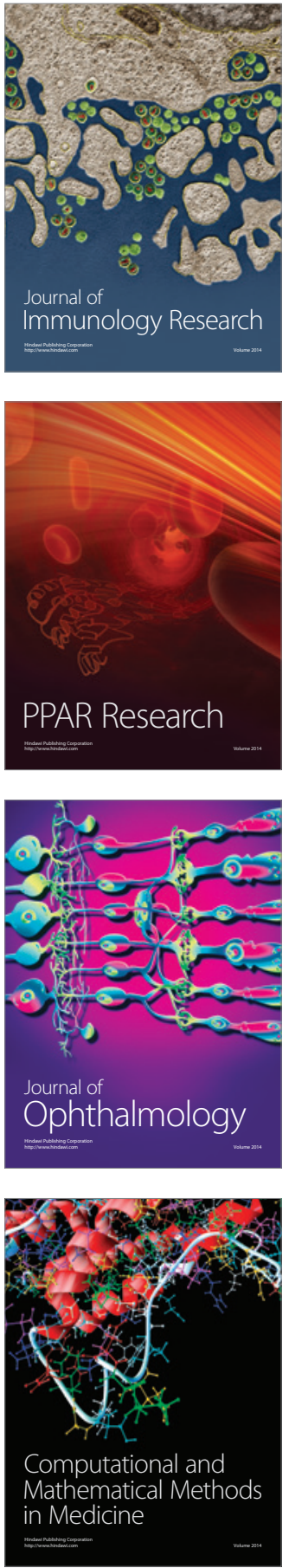

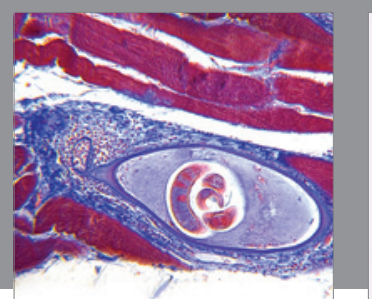

Gastroenterology Research and Practice

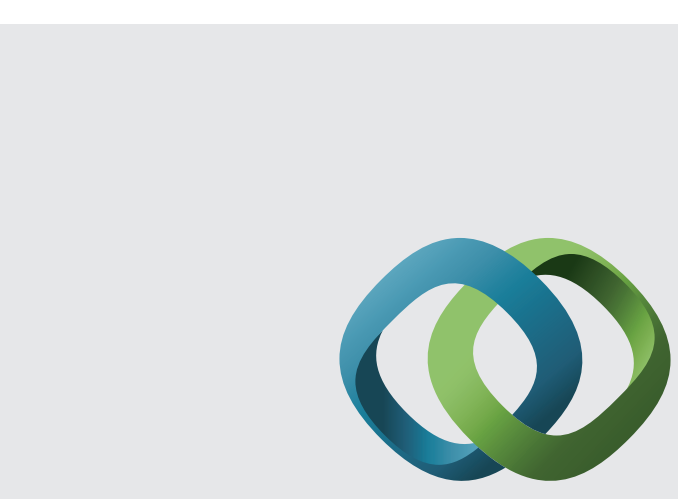

\section{Hindawi}

Submit your manuscripts at

http://www.hindawi.com
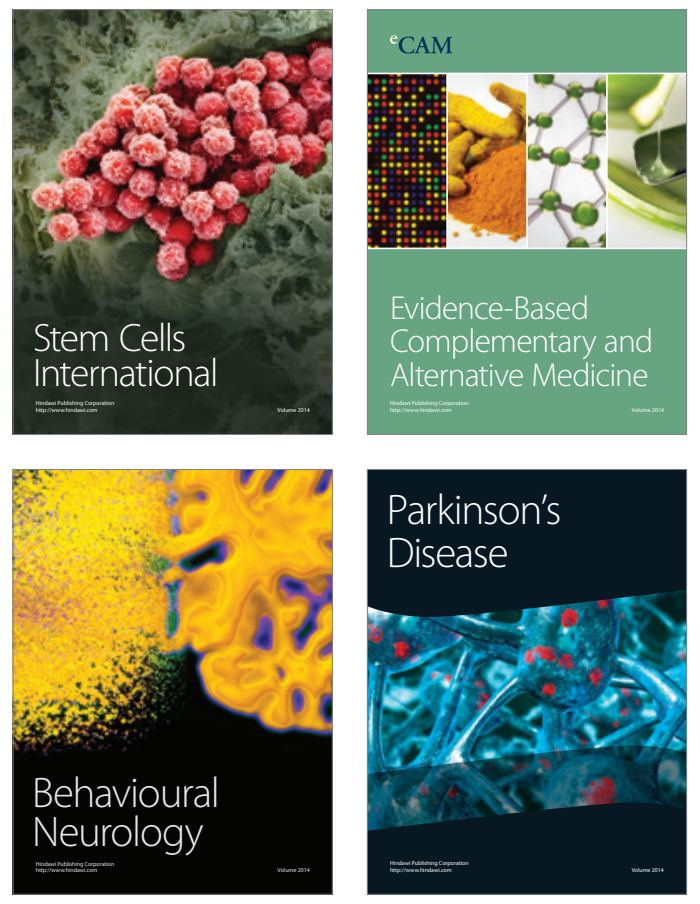
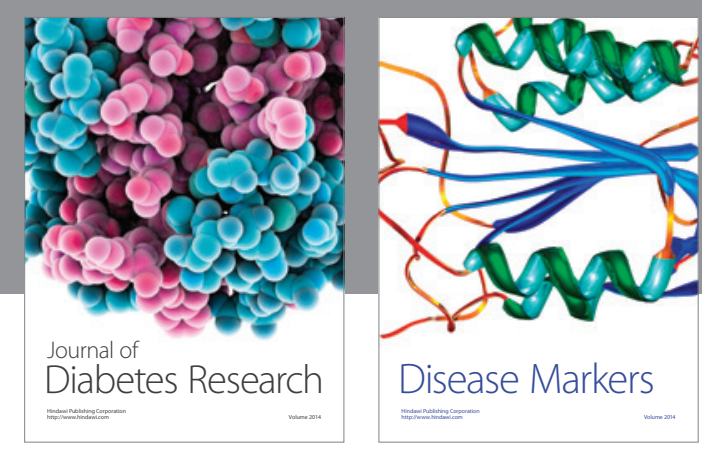

Disease Markers
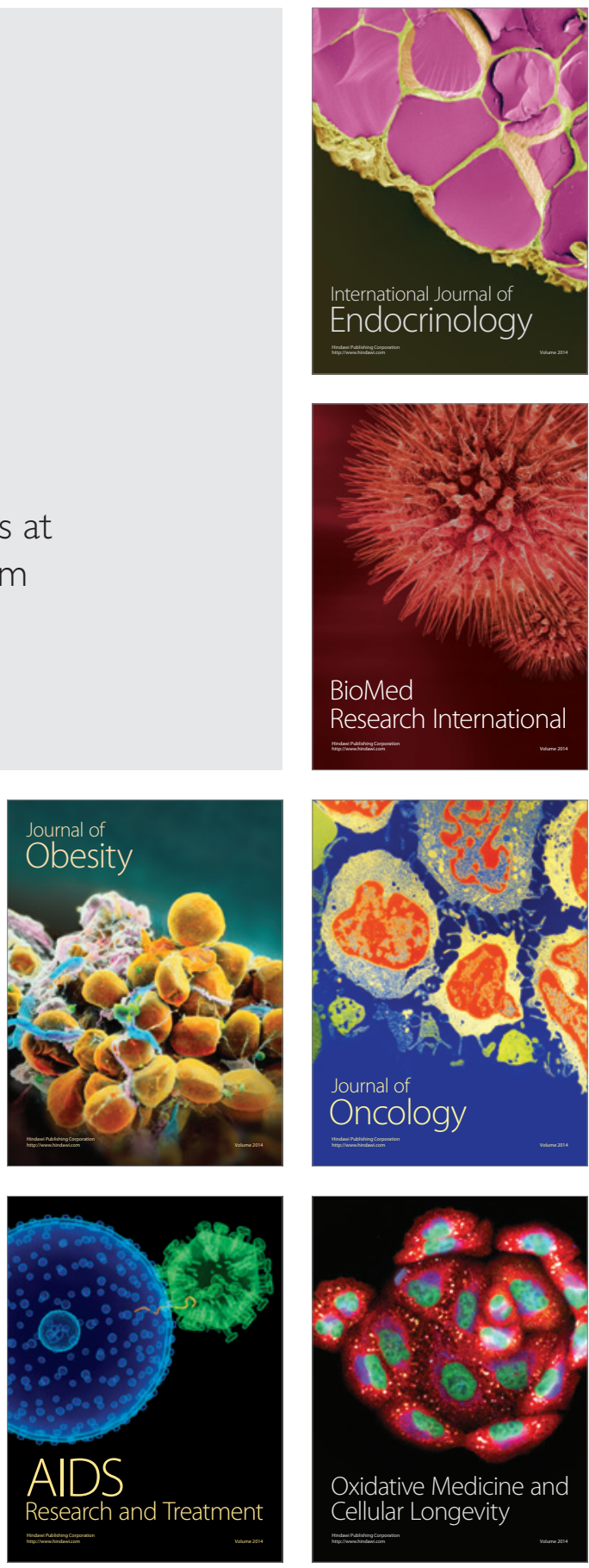